\title{
The Association Between Extracellular Water-to-Total Body Water Ratio and Therapeutic Durability for Advanced Lung Cancer
}

\author{
YOSHIMI NODA, HIDEKAZU SUZUKI, TOMOHIRO KANAI, YUMIKO SAMEJIMA, SHINGO NASU, \\ AYAKO TANAKA, NAOKO MORISHITA, NORIO OKAMOTO and TOMONORI HIRASHIMA \\ Department of Thoracic Oncology, Osaka Habikino Medical Center, Osaka, Japan
}

\begin{abstract}
Background/Aim: Extracellular water-to-total body water ratio $(E C W / T B W)$ measured by bioelectrical impedance analysis (BIA) reportedly predicts clinical outcomes of various diseases. The aim of this retrospective study was to examine the association between ECW/TBW and therapeutic durability of chemotherapy and/or immune checkpoint inhibitors in advanced lung cancer. Patients and Methods: Patients with advanced lung cancer underwent BIA before chemotherapy and/or treatment with immune checkpoint inhibitors at our hospital between June 2018 and November 2019. Results: Of 75 patients, 18 with $E C W / T B W \geq 0.4$ were assigned to the overhydrated group $(\mathrm{OH}-\mathrm{G})$ and 57 patients $E C W / T B W<0.4$ were assigned to the non-overhydrated group (NOH-G). The median time-to-treatment failure was significantly shorter in the $\mathrm{OH}-\mathrm{G}$ than in the $\mathrm{NOH}-\mathrm{G}(\mathrm{p}=0.003)$. Multivariate analysis revealed that $E C W / T B W \geq 0.4$ predicted treatment failure [hazard ratio $(H R)=2.508,95 \%$ confidence interval $(C I)=1.19$ 5.27; $p=0.01]$. Conclusion: The ECW/TBW may be an objective parameter for predicting therapeutic durability in advanced lung cancer.
\end{abstract}

The treatments for lung cancer have rapidly evolved, and the selection of a specific treatment strategy is typically based on various factors, including the patient's general condition (1, 2), as measured by the Eastern Cooperative Oncology Group performance status (ECOG PS) (3). Patients with good to moderate PS (PS 0-2) are expected to tolerate treatment well.

This article is freely accessible online.

Correspondence to: Yoshimi Noda, Department of Thoracic Oncology, Osaka Habikino Medical Center, 3-7-1 Habikino, Habikino-City, Osaka 583-8588, Japan. Tel: +81 729572121, Fax: +81729578002, e-mail: y.noda443@ra.opho.jp

Key Words: Lung cancer, bioelectrical impedance analysis, $\mathrm{ECW} / \mathrm{TBW}$, prognostic factor.
However, PS is also subjectively assessed based on the clinician's judgement, which can introduce some heterogeneity. The Comprehensive Geriatric Assessment is a widely used method for evaluating the medical, psychological, and functional status of older patients (4), although its clinical application is limited by the substantial time needed for the valuation. Therefore, other objective parameters are needed to predict clinical outcomes. Bioelectrical impedance analysis (BIA) has recently attracted attention as a simple and noninvasive tool for objectively predicting clinical outcomes in cancer patients, by evaluating malnutrition and cancer cachexia $(5,6)$. The BIA evaluation is performed by sending a weak electrical current through the body and measuring related parameters $(7,8)$. Among the BIA parameters, the extracellular water to total body water ratio $(\mathrm{ECW} / \mathrm{TBW})$ is a useful indicator for nutritional assessments $(7,9)$, as it measures the body's water balance in the blood and interstitial fluid (i.e., an edema index), with malnutrition being reflected in an increased proportion of extracellular water (9). A high ECW/TBW is also reportedly useful for identifying a poor general condition and predicting clinical outcomes among patients with chronic liver diseases (10-12), renal disorders (13, 14), heart failure $(15,16)$, and critical illness (9). However, we are not aware of any data regarding the relationship between ECW/TBW and lung cancer outcomes. Therefore, we aimed to clarify this relationship among patients who had received treatment for advanced lung cancer.

\section{Patients and Methods}

Patient selection and testing parameters. This retrospective study included patients with advanced lung cancer who received chemotherapy and/or immune checkpoint inhibitors at Osaka Habikino Medical Center between June 2018 and November 2019. However, patients who received molecular-targeted therapy for advanced lung cancer were excluded from this study.

Clinical records of the patients were reviewed to collect baseline data regarding age, gender, smoking status (never, former, current), ECOG PS (0-3), conditions that might affect the BIA readings (liver 
dysfunction, renal disorders, and heart failure) (10-16), histology (adenocarcinoma, squamous cell carcinoma, small cell carcinoma, others), disease stage (III, IV, recurrence) (17), treatment regimen, and previous lines of treatments $(0 / \geq 1)$. The initial treatment and all subsequent treatments were included in the analyses. Laboratory data were collected regarding lymphocyte count, the neutrophil-tolymphocyte ratio, serum albumin $(\mathrm{g} / \mathrm{dl})$, and serum C-reactive protein $(\mathrm{mg} / \mathrm{dl})$.

BIA testing. A multi-frequency BIA scanner (InBody770; InBody, Seoul, Republic of Korea) was used to collect data regarding the patient's fat-free mass, total body water (TBW), extracellular water $(E C W)$, and intracellular water. Segmental resistances were measured using eight surface electrodes at the thumbs, fingers, balls of the feet, and heels while the patient kept both arms abducted. Microprocessorcontrolled switches and an impedance analyzer were activated in the sensors to measure segmental resistance at six frequencies $(1 \mathrm{kHz}, 5$ $\mathrm{kHz}, 50 \mathrm{kHz}, 250 \mathrm{kHz}, 500 \mathrm{kHz}$, and 1,000 kHz). These frequencies allow for separate measurements of intracellular and extracellular water, as low frequencies travel through extracellular water and cannot penetrate cell membranes, while high frequencies can penetrate cell membranes. Among the various BIA parameters, the present study evaluated the pre-treatment values for the ECW/TBW, with high values (i.e., fluid overload) defined as $\geq 0.4(11,18-20)$. Using this cut-off point, the patients were classified into two groups: the overhydrated group (OH-G) with ECW/TBW $\geq 0.4$ and the nonoverhydrated group (NOH-G) with ECW/TBW $<0.4$.

Clinical outcomes. The outcomes of interest were the time-totreatment failure (TTF), overall survival (OS), and severe adverse events. TTF was defined as the time from the BIA measurement to treatment failure owing to progressive disease (PD), severe adverse events, or deterioration of the patient's PS, within 1 year. The OS interval was calculated from the BIA measurement until death of the patient, within 1 year. Grade 3-4 adverse events during the first month after the BIA measurement were evaluated according to version 5.0 of the Common Terminology Criteria for Adverse Events (21). This observational period was selected in order to focus on the adverse events for 1 cycle of chemotherapy and/or immune checkpoint inhibitors.

Statistical analysis. Characteristics were compared between the two groups using the Mann-Whitney $U$-test and the Pearson's chisquared test, as appropriate. The Kaplan-Meier method and log-rank test were used to compare the curves for TTF and OS. Furthermore, a Cox proportional hazard model was used to evaluate these outcomes, with the results reported as the hazard ratio (HR) and 95\% confidence interval (CI). Differences were considered statistically significant at $p$-values of $<0.05$. All statistical analyses were performed using R software (version 3.3.2).

Ethical and consent to participate. The study's retrospective protocol was approved by the institutional review board of the Osaka Habikino Medical Center (formerly the Osaka Prefectural Medical Center for Respiratory and Allergic Diseases, Osaka, Japan) on March 5, 2020 (approval no.: 1010). The requirement for informed consent was waived based on the retrospective design and use of anonymized data. All research protocols complied with the 1964 Declaration of Helsinki and its later amendments. Details regarding our center's optout policy are available at: http://www.ra.opho.jp/hospital/110/.
Table I. Baseline characteristics of patients.

\begin{tabular}{|c|c|c|c|}
\hline & $\begin{array}{c}\text { ECW/TBW } \\
\text { of }<0.4 \\
(\mathrm{~N}=57)\end{array}$ & $\begin{array}{c}\text { ECW/TBW } \\
\text { of } \geq 0.4 \\
(\mathrm{~N}=18)\end{array}$ & $p$-Value \\
\hline \multicolumn{4}{|l|}{ Age, years } \\
\hline Median (range) & $72(44-83)$ & $77(60-85)$ & 1.00 \\
\hline \multicolumn{4}{|l|}{ Gender, $\mathrm{n}$} \\
\hline Male & $44(77.2 \%)$ & $12(66.7 \%)$ & 0.37 \\
\hline Female & $13(22.8 \%)$ & $6(33.3 \%)$ & \\
\hline \multicolumn{4}{|l|}{ ECOG PS, $n$} \\
\hline 0 & $11(19.3 \%)$ & $0(0 \%)$ & 0.001 \\
\hline 1 & $40(70.2 \%)$ & $9(50.5 \%)$ & \\
\hline 2 & $6(10.5 \%)$ & $8(44.4 \%)$ & \\
\hline 3 & $0(0 \%)$ & $1(5.6 \%)$ & \\
\hline \multicolumn{4}{|l|}{ Smoking status, $\mathrm{n}$} \\
\hline Never & $7(12.3 \%)$ & $6(33.3 \%)$ & 0.30 \\
\hline Current or former & $50(87.7 \%)$ & $12(66.7 \%)$ & \\
\hline \multicolumn{4}{|l|}{$\begin{array}{l}\text { Conditions that might } \\
\text { influence the BIA readings, } \mathrm{n}\end{array}$} \\
\hline Yes & $1(1.8 \%)$ & $1(5.6 \%)$ & 0.97 \\
\hline No & $56(98.2 \%)$ & $17(94.4 \%)$ & \\
\hline \multicolumn{4}{|l|}{ Histological type, $\mathrm{n}$} \\
\hline Adenocarcinoma & $33(57.9 \%)$ & $11(61.1 \%)$ & 0.40 \\
\hline Squamous cell carcinoma & $11(19.3 \%)$ & $6(33.3 \%)$ & \\
\hline SCLC & $9(15.8 \%)$ & $1(5.6 \%)$ & \\
\hline Others & $4(7.0 \%)$ & $0(0 \%)$ & \\
\hline \multicolumn{4}{|l|}{ Stage, $n$} \\
\hline III & $10(17.5 \%)$ & $6(33.3 \%)$ & 0.30 \\
\hline IV & $25(43.9 \%)$ & $8(44.4 \%)$ & \\
\hline Recurrence & $22(38.6 \%)$ & $4(22.2 \%)$ & \\
\hline \multicolumn{4}{|l|}{ Treatment regimen, $\mathrm{n}$} \\
\hline $\mathrm{CT}$ & $36(63.2 \%)$ & $15(83.3 \%)$ & 0.26 \\
\hline ICI & $15(26.3 \%)$ & $3(16.7 \%)$ & \\
\hline CT plus ICI & $6(10.5 \%)$ & $0(0 \%)$ & \\
\hline \multicolumn{4}{|l|}{ Treatment line, $\mathrm{n}$} \\
\hline 1 & $34(59.6 \%)$ & $11(61.1 \%)$ & 1.00 \\
\hline$\geq 2$ & $23(40.4 \%)$ & $7(38.9 \%)$ & \\
\hline \multicolumn{4}{|l|}{ Lymphocyte count $\left(/ \mathrm{mm}^{3}\right)$} \\
\hline Median (range) & $\begin{array}{c}1,380 \\
(600-3,090)\end{array}$ & $\begin{array}{c}1,170 \\
(350-2,050)\end{array}$ & 0.176 \\
\hline \multicolumn{4}{|l|}{ Neutrophil-to-lymphocyte ratio } \\
\hline Median (range) & $\begin{array}{c}3.25 \\
(1.05-11.22)\end{array}$ & $\begin{array}{c}3.99 \\
(1.82-12.60)\end{array}$ & 0.169 \\
\hline \multicolumn{4}{|l|}{ Albumin (g/dl) } \\
\hline Median (range) & $\begin{array}{c}4.00 \\
(2.70-4.80)\end{array}$ & $\begin{array}{c}3.60 \\
(2.20-4.50)\end{array}$ & 0.002 \\
\hline \multicolumn{4}{|l|}{ C-reactive protein $(\mathrm{mg} / \mathrm{dl})$} \\
\hline Median (range) & $\begin{array}{c}0.32 \\
(0.03-8.48)\end{array}$ & $\begin{array}{c}0.48 \\
(0.02-17.93)\end{array}$ & 0.51 \\
\hline
\end{tabular}

ECOG PS: Eastern Cooperative Oncology Group performance status; ECW/TBW: extracellular water to total body water ratio; SCLC: small cell lung cancer; CT: chemotherapy; ICI: immune checkpoint inhibitor.

\section{Results}

Patient characteristics and laboratory findings. This study included 75 patients with advanced lung cancer and their baseline characteristics are shown in Table I. A total of 18 
Table II. Univariate and multivariate analyses of risk factors related to treatment failure.

\begin{tabular}{lccc}
\hline & $\begin{array}{c}\text { Univariate analysis } \\
\text { HR }(95 \% \mathrm{CI})\end{array}$ & $p$-Value & $\begin{array}{c}\text { Multivariate analysis } \\
\text { HR (95\% CI) }\end{array}$ \\
\hline Age $\geq 75$ years & $1.29(0.76-2.18)$ & 0.34 & \\
Gender Male & $1.02(0.56-1.85)$ & 0.95 & \\
ECOG PS of 2-3 & $1.63(0.86-3.11)$ & 0.135 & \\
Current or former smoker & $0.59(0.31-1.13)$ & 0.114 & \\
Conditions that might influence the BIA readings & $2.74(0.66-11.38)$ & 0.167 & \\
Treatment using ICIs & $0.99(0.56-1.73)$ & 0.96 & \\
Treatment line of $\geq 2$ & $1.27(0.74-2.17)$ & 0.39 & $1.48(0.55-4.00)$ \\
Serum albumin of $\leq 3.0 \mathrm{~g} / \mathrm{dl}$ & $2.27(0.89-5.75)$ & 0.085 & 0.44 \\
ECW/TBW of $\geq 0.4$ & $2.35(1.30-4.23)$ & 0.005 & $2.18(1.16-4.08)$ \\
\hline
\end{tabular}

HR: Hazard ratio; CI: confidence interval; ECOG PS: Eastern Cooperative Oncology Group performance status; ECW/TBW: extracellular water to total body water ratio.

Table III. Univariate and multivariate analyses of factors related to overall survival.

\begin{tabular}{lccc}
\hline & $\begin{array}{c}\text { Univariate analysis } \\
\text { HR }(95 \% \mathrm{CI})\end{array}$ & $p$-Value & $\begin{array}{c}\text { Multivariate analysis } \\
\text { HR }(95 \% \text { CI) }\end{array}$ \\
\hline Age $\geq 75$ years & $0.61(0.24-1.54)$ & 0.30 & \\
Gender Male & $1.53(0.51-4.57)$ & 0.45 & \\
ECOG PS of 2-3 & $3.64(1.48-8.96)$ & 0.005 & $2.71(0.95-7.72)$ \\
Current or former smoker & $0.63(0.23-1.74)$ & 0.37 & \\
Conditions that might influence the BIA readings & $4.97(0.64-38.68)$ & 0.126 & \\
Treatment using ICIs & $0.40(0.13-1.20)$ & 0.104 & \\
Treatment line of $\geq 2$ & $1.77(0.74-4.27)$ & 0.20 & $1.83(0.49-6.80)$ \\
Serum albumin of $\leq 3.0 \mathrm{~g} / \mathrm{dl}$ & $3.13(0.91-10.73)$ & 0.070 & $1.54(0.56-4.27)$ \\
ECW/TBW of $\geq 0.4$ & $2.47(1.01-6.06)$ & 0.048 & 0.37 \\
\hline
\end{tabular}

HR: Hazard ratio; CI: confidence interval; ECOG PS: Eastern Cooperative Oncology Group performance status; ECW/TBW: extracellular water to total body water ratio.

patients were assigned to the OH-G based on ECW/TBW $\geq 0.4$ and 57 were assigned to the NOH-G based on ECW/TBW $<0.4$. The OH-G had a higher proportion of patients with a PS of $2-3$ than the NOH-G $(50.0 \% \mathrm{vs}$. $10.5 \%, p=0.001)$. Furthermore, the OH-G had a significantly lower median serum albumin concentration than the NOH-G $(p=0.002)$. No other significant differences were observed in the clinicopathological characteristics between the two groups.

Relationship between the ECW/TBW and TTF. As shown in Figure 1, the OH-G had a significantly shorter median TTF than the NOH-G (1.9 vs. 4.9 months, HR: $2.35,95 \%$ $\mathrm{CI}=1.30-4.23$; log-rank $p=0.003)$. Sixteen patients in the $\mathrm{OH}-\mathrm{G}$ experienced treatment failure due to PD (10 patients, $62.5 \%$ ), adverse events (4 patients, $25.0 \%$ ), or a worsened general condition (2 patients, 12.5\%). Forty patients in the NOH-G group experienced treatment failure; specifically, PD $(n=28,70.0 \%)$, adverse events $(n=9,22.5 \%)$, or a worsened general condition $(n=3,7.5 \%)$ were observed. The results of the multivariate analyses (Table II) revealed that the only independent predictor of treatment failure was the $\mathrm{ECW} / \mathrm{TBW} \quad(\mathrm{HR}=2.51,95 \%$ $\mathrm{CI}=1.19-5.27 ; p=0.01)$.

Relationship between the ECW/TBW and OS. Figure 2 shows that the NOH-G had significantly better OS than the OH-G $(\mathrm{HR}=2.47,95 \% \mathrm{CI}=1.01-6.06 ;$ log-rank $p=0.04)$. The median OS was not reached in either group. In multivariate analysis, none of the examined factors was independently associated with OS (Table III).

Grade 3-4 adverse events during the first month. Table IV shows that the two groups did not have significantly different rates of Grade 3-4 adverse events during the first month after the BIA. However, the $\mathrm{OH}-\mathrm{G}$ tended to have higher rates of non-hematological grade 3-4 adverse events, such as anorexia and infection. 


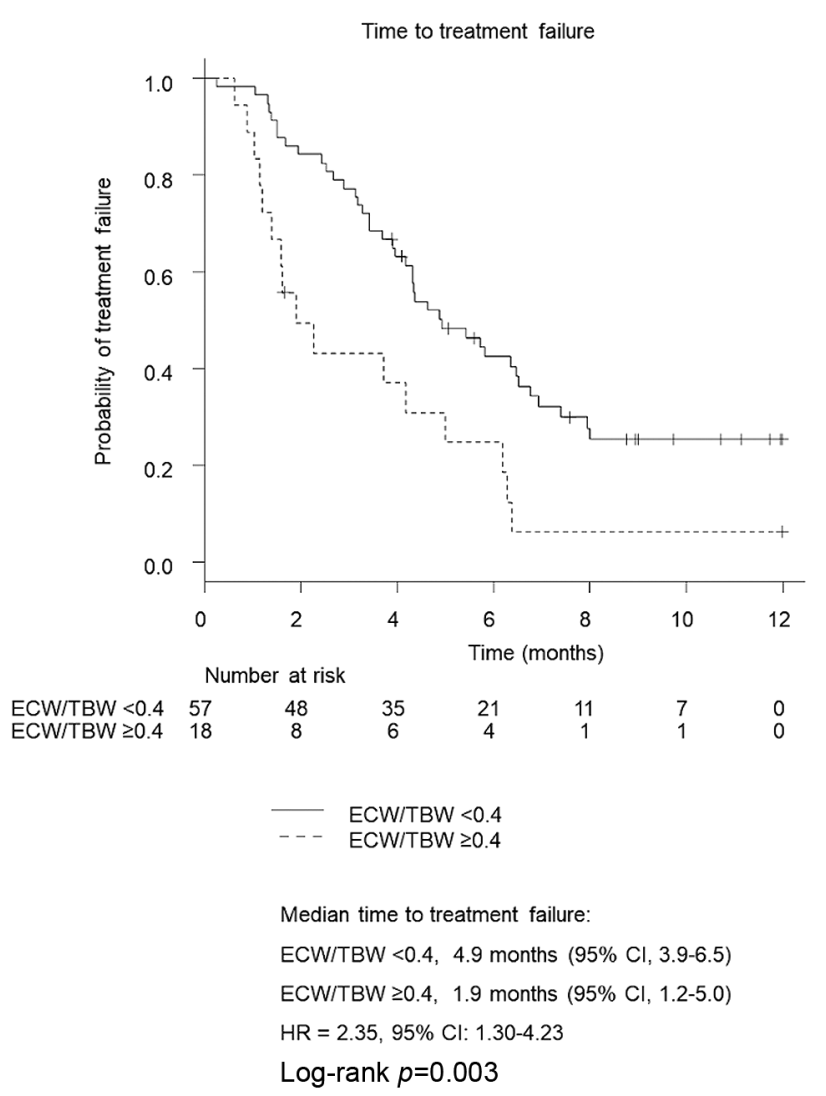

Figure 1. Kaplan-Meier plot of the time-to-treatment failure according to the extracellular water-to-total body water ratio (ECW/TBW). HR: Hazard ratio; CI: confidence interval; NA: not available.

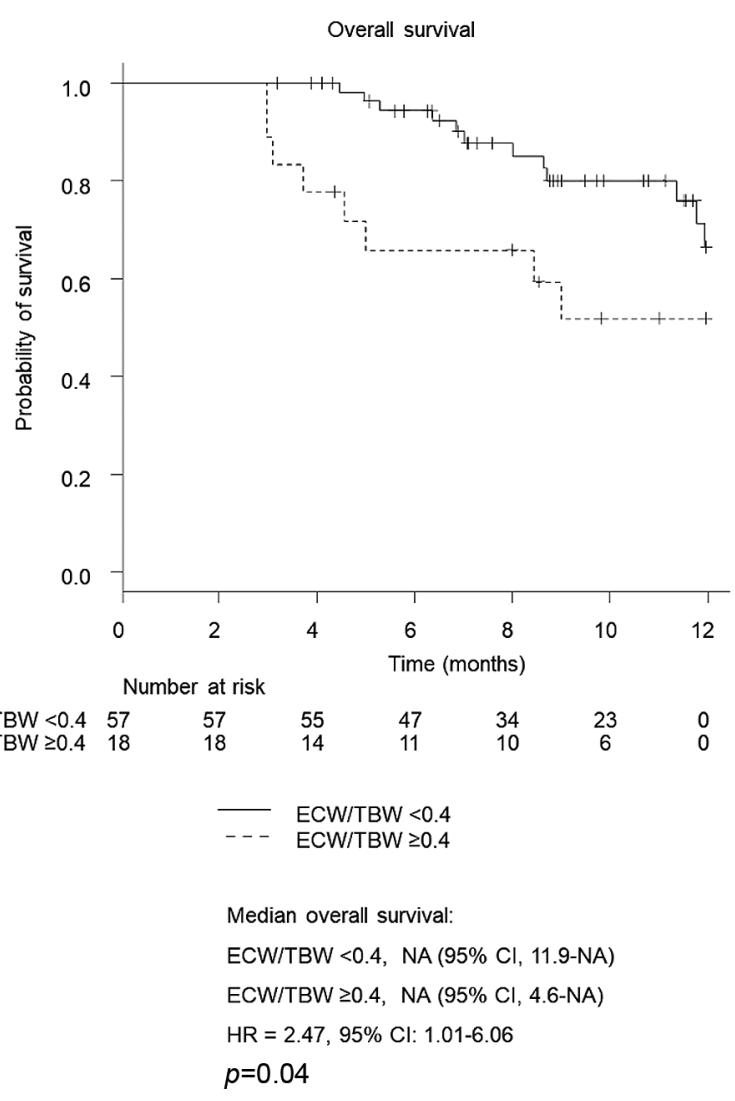

Figure 2. Kaplan-Meier plot of the overall survival according to the extracellular water-to-total body water ratio (ECW/TBW). HR: Hazard ratio; CI: confidence interval; NA: not available.

Table IV. Treatment-related grade 3-4 severe adverse events.

\begin{tabular}{lccc}
\hline & ECW/TBW of $<0.4(\mathrm{~N}=57)$ & ECW/TBW of $\geq 0.4(\mathrm{~N}=18)$ & $p$-Value \\
\hline All events, $\mathrm{n}(\%)$ & $29(50.9 \%)$ & $10(55.6 \%)$ & $8(44.4 \%)$ \\
Hematological events, $\mathrm{n}(\%)$ & $23(40.4 \%)$ & $7(38.9 \%)$ & 0.79 \\
Decreased white blood cell or neutrophil count & $22(38.6 \%)$ & $1(5.6 \%)$ \\
Anemia & $0(0 \%)$ & $0(0 \%)$ & $6(33.3 \%)$ \\
Decreased platelet count & $2(3.5 \%)$ & $2(11.1 \%)$ \\
Non-hematological events, $\mathrm{n}(\%)$ & $10(17.5 \%)$ & $4(22.2 \%)$ \\
Nausea and anorexia & $1(1.8 \%)$ & $0(0 \%)$ \\
Infection & $4(7.0 \%)$ & $0(0 \%)$ \\
Gastric ulcer & $1(1.8 \%)$ & $0(0 \%)$ \\
Increased alanine or aspartate aminotransferase & $1(1.8 \%)$ & $2(3.5 \%)$ & 0.191 \\
Allergic reaction or anaphylaxis & & \\
\hline
\end{tabular}

ECW/TBW: Extracellular water to total body water ratio.

\section{Discussion}

The present study revealed that an overhydrated state (ECW/TBW $\geq 0.4$ ) predicted treatment failure of chemotherapy and/or immune checkpoint inhibitors among patients with advanced lung cancer. In addition, nonhematological grade 3-4 adverse events, such as anorexia and infection, were more common in the group with 
ECW/TBW $\geq 0.4$; however, this finding did not reach statistical significance. To the best of our knowledge, this is the first report to identify relationships between the ECW/TBW and clinical outcomes after treatment for advanced lung cancer.

Previous studies have indicated that the ECW/TBW is associated with clinical outcomes in cases involving chronic liver diseases, renal disorders, heart failure, and critical illness. This is because these conditions are mechanistically linked to extracellular osmolality. For example, advanced lung cancer leads to cachexia, which causes malnutrition and loss of skeletal muscle mass and function (i.e., sarcopenia) $(22,23)$. This process leads to the loss of intracellular or body cell mass, with a corresponding expansion of extracellular mass. Other recent reports have also indicated that chronic inflammation may cause hyperosmotic stress, which involves an increase in extracellular osmolality, and plays an important role in carcinogenesis $(24,25)$. The balance between extracellular and intracellular osmolality is maintained via regulation of cell volume (i.e., cell-volume homeostasis), which is critical because disruption of cellular osmoregulatory mechanisms can cause various diseases and complications (26). An increase in extracellular osmolality leads to intracellular dehydration, which results in structural damage to proteins that in turn causes altered enzymatic functions in the nucleus, mitochondria, and cytoskeleton (25, $27,28)$. Accumulation of these changes and cell damage leads to apoptosis, which subsequently causes decreased muscle strength, gait instability, falls, fractures, respiratory infections, confusion, renal failure, increased medication toxicity, and an increased risk of death $(25,28,29)$. Based on previous studies that have indicated an association between a high ECW/TBW and postoperative complications, such as infection $(30,31)$, we hypothesized that a high ECW/TBW might predict poor clinical outcomes after treatment for advanced lung cancer, and our findings appear to support this hypothesis.

Phase angle (PA) is an index of the healthy body cell mass and is used to evaluate a subject's nutritional status and potentially predict mortality in patients with various malignancies, including lung cancer (8, 32, 33). Nevertheless, the appropriate cut-off value for PA is unclear, as previous studies have used different cut-off values (6). In contrast, previous studies have indicated that the ECW/TBW of healthy persons is maintained at 0.38 , with values of $\geq 0.4$ in edematous persons $(11,18-20)$. As the $\mathrm{ECW} / \mathrm{TBW}$ is reportedly related to the volume of lung cancer (34), we considered whether it might be a useful prognostic marker in patients who received treatment for advanced lung cancer. Our univariate analyses revealed significantly better OS in the $\mathrm{OH}-\mathrm{G}$ than in the $\mathrm{NOH}-\mathrm{G}$, although the multivariate analyses failed to confirm that the ECW/TBW could independently predict OS at 1 year. The reasons for the lack of an independent association are not clear, although it is possible that the ECW/TBW should be considered a dynamic factor, rather than a static factor, as the value changes according to the patient's condition (31).

The present study has several limitations. First, the retrospective single-center design is prone to bias. Second, the small sample size may also be a source of bias. Third, we were not able to evaluate the patients' cardiac function, which might influence the ECW/TBW as an edema index. Further prospective studies are needed to confirm whether the ECW/TBW predicts long-term OS, or whether it exhibits dynamic changes according to the patient's general condition and treatment response.

In conclusion, ECW/TBW $\geq 0.4$ was significantly associated with treatment failure at 1 year. Thus, ECW/TBW $\geq 0.4$ may be an objective parameter for predicting the therapeutic durability for advanced lung cancer.

\section{Conflicts of Interest}

T.H. received honoraria and research funding from Ono Pharmaceutical Co. Ltd. (Osaka, Japan), Lilly Japan Co. Ltd. (Hyogo, Japan), AstraZeneca Co. Ltd. (Osaka, Japan), Taiho Pharmaceutical Co. Ltd. (Tokyo, Japan), Chugai Pharmaceutical Co. Ltd. (Tokyo, Japan), Merck Serono Co. Ltd. (Tokyo, Japan), MSD Oncology Co. Ltd. (Tokyo, Japan), Kyowa-Hakko Kirin, and Boehringer Ingelheim. The remaining Authors have no conflicts of interest to report.

\section{Authors' Contributions}

All Authors were involved in the study's conception and design; the data acquisition, analysis, or interpretation; drafting or revising the article for important intellectual content; and provided final approval of the submitted version. YN and TH collected the multifrequency BIA data. YN and HS performed the statistical analyses.

\section{Acknowledgements}

The Authors thank the patients and their families, the research staff at the Department of Thoracic Oncology (Yuko Tani and Kiyoko Shiraishi), and Editage (www.editage.jp) for English language editing.

\section{References}

1 Carmichael JA, Wing-San Mak D and O'Brien M: A review of recent advances in the treatment of elderly and poor performance NSCLC. Cancers (Basel) 10(7): 236, 2018. PMID: 30021993. DOI: $10.3390 /$ cancers 10070236

2 Ettinger DS, Wood DE, Aggarwal C, Aisner DL, Akerley W, Bauman JR, Bharat A, Bruno DS, Chang JY, Chirieac LR, D'Amico TA, Dilling TJ, Dobelbower M, Gettinger S, Govindan R, Gubens MA, Hennon M, Horn L, Lackner RP, Lanuti M, Leal TA, Lin J, Loo BW, Jr., Martins RG, Otterson GA, Patel SP, Reckamp KL, Riely GJ, Schild SE, Shapiro TA, Stevenson J, Swanson SJ, Tauer KW, Yang SC, Gregory K, Ocn and Hughes 
M: NCCN guidelines insights: Non-small cell lung cancer, version 1.2020. J Natl Compr Canc Netw 17(12): 1464-1472, 2019. PMID: 31805526 . DOI: $10.6004 /$ jncen.2019.0059

3 ECOG Performance Status: ECOG-ARCIN Cancer Research Group, 2020. Available at: https://ecog-acrin.org/resources/ecogperformance-status. [Last accessed on May 21, 2020]

4 Extermann M and Hurria A: Comprehensive geriatric assessment for olderpatients with cancer. J Clin Oncol 25(14): 1824-1831, 2007. PMID: 17488980. DOI: 10.1200/JCO.2007.10.6559

5 Hilal Z, Rezniczek GA, Klenke R, Dogan A and Tempfer CB: Nutritional status, cachexia, and anorexia in women with peritoneal metastasis and intraperitoneal chemotherapy: alongitudinal analysis. J Gynecol Oncol 28(6): e80, 2017. PMID: 29027398. DOI: 10.3802/jgo.2017.28.e80

6 Pereira MME, Queiroz MDSC, de Albuquerque NMC, Rodrigues J, Wiegert EVM, Calixto-Lima L and de Oliveira LC: The prognostic role of phase angle in advanced cancer patients: asystematic review. Nutr Clin Pract 33(6): 813-824, 2018. PMID: 29786894. DOI: 10.1002/ncp.10100

7 Kyle UG, Bosaeus I, De Lorenzo AD, Deurenberg P, Elia M, Gómez JM, Heitmann BL, Kent-Smith L, Melchior JC, Pirlich M, Scharfetter H, Schols AM, Pichard C and Composition of the ESPEN Working Group: Bioelectrical impedance analysis-part I: review of principles and methods. Clin Nutr 23(5): 1226-1243, 2004. PMID: 15380917. DOI: 10.1016/j.clnu.2004.06.004

8 Kyle UG, Bosaeus I, De Lorenzo AD, Deurenberg P, Elia M, Manuel Gómez J, Lilienthal Heitmann B, Kent-Smith L, Melchior JC, Pirlich M, Scharfetter H, M W J Schols A, Pichard $\mathrm{C}$ and ESPEN: Bioelectrical impedance analysis-part II: utilization in clinical practice. Clin Nutr 23(6): 1430-1453, 2004. PMID: 15556267. DOI: 10.1016/j.clnu.2004.09.012

9 Lee Y, Kwon O, Shin CS and Lee SM: Use of bioelectrical impedance analysis for the assessment of nutritional status in critically ill patients. Clin Nutr Res 4(1): 32-40, 2015. PMID: 25713790. DOI: $10.7762 / \mathrm{cnr} .2015 .4 .1 .32$

10 Kahraman A, Hilsenbeck J, Nyga M, Ertle J, Wree A, Plauth M, Gerken G and Canbay AE: Bioelectrical impedance analysis in clinical practice: implications for hepatitis $\mathrm{C}$ therapy BIA and hepatitis C. Virol J 7: 191, 2010. PMID: 20712878. DOI: 10.1186/1743-422X-7-191

11 Nishikawa H, Yoh K, Enomoto H, Ishii N, Iwata Y, Nakano C, Takata R, Nishimura T, Aizawa N, Sakai Y, Ikeda N, Hasegawa K, Takashima T, Iijima H and Nishiguchi S: Extracellular water to total body water ratio in viral liver diseases: a study using bioimpedance analysis. Nutrients 10(8): 1072, 2018. PMID: 30103528. DOI: $10.3390 /$ nu 10081072

12 Kishino K, Enomoto H, Shimono Y, Moriwaki EI, Nishikawa H, Nishimura T, Iwata Y, Iijima $\mathrm{H}$ and Nishiguchi S: Association of an overhydrated state with the liver fibrosis and prognosis of cirrhotic patients. In Vivo 34(3): 1347-1353, 2020. PMID: 32354929. DOI: 10.21873/invivo.11912

13 Han BG, Song SH, Yoo JS, Park H, Kim J and Choi E: Association between $\mathrm{OH} / \mathrm{ECW}$ and echocardiographic parameters in CKD5 patients not undergoing dialysis. PLoS One 13(4): e0195202, 2018. PMID: 29630661. DOI: 10.1371/journal.pone.0195202

14 Ohashi Y, Otani T, Tai R, Tanaka Y, Sakai K and Aikawa A: Assessment of body composition using dry mass index and ratio of total body water to estimated volume based on bioelectrical impedance analysis in chronic kidney disease patients. J Ren Nutr 23(1): 28-36, 2013. PMID: 22406124. DOI: 10.1053/j.jrn.2011.12.006
15 Liu MH, Wang CH, Huang YY, Tung TH, Lee CM, Yang NI, Liu PC and Cherng WJ: Edema index established by a segmental multifrequency bioelectrical impedance analysis provides prognostic value in acute heart failure. J Cardiovasc Med (Hagerstown) 13(5): 299-306, 2012. PMID: 22367574. DOI: 10.2459/JCM.0b013e328351677f

16 Park CS, Lee SE, Cho HJ, Kim YJ, Kang HJ, Oh BH and Lee HY: Body fluid status assessment by bio-impedance analysis in patients presenting to the emergency department with dyspnea. Korean J Intern Med 33(5): 911-921, 2018. PMID: 29241303. DOI: $10.3904 / \mathrm{kjim} .2016 .358$

17 Goldstraw P, Chansky K, Crowley J, Rami-Porta R, Asamura H, Eberhardt WE, Nicholson AG, Groome P, Mitchell A, Bolejack V, International Association for the Study of Lung Cancer S, Prognostic Factors Committee AB, Participating I, International Association for the Study of Lung Cancer S, Prognostic Factors Committee Advisory B and Participating I: The IASLC lung cancer staging project: Proposals for revision of the TNM stage groupings in the forthcoming (eighth) edition of the TNM classification for lung cancer. $\mathbf{J}$ Thorac Oncol 11(1): 39-51, 2016. DOI: 10.1016/j.jtho. 2015.09.009

18 Davenport A, Sayed RH and Fan S: Is extracellular volume expansion of peritoneal dialysis patients associated with greater urine output? Blood Purif 32(3): 226-231, 2011. PMID: 21829014. DOI: 10.1159/000329732

19 Papakrivopoulou E, Booth J, Pinney J and Davenport A: Comparison of volume status in asymptomatic haemodialysis and peritoneal dialysis outpatients. Nephron Extra 2(1): 48-54, 2012. PMID: 22619667. DOI: 10.1159/000337338

20 Guo Q, Yi C, Li J, Wu X, Yang X and Yu X: Prevalence and risk factors of fluid overload in Southern Chinese continuous ambulatory peritoneal dialysis patients. PLoS One 8(1): e53294, 2013. PMID: 23341936. DOI: 10.1371/journal.pone.0053294

21 Cancer Therapy Evaluation Program (CTEP): Common Terminology Criteria for Adverse Events (CTCAE). Bethesda, National Institutes of Health, 2020. Available at: https://ctep.cancer. gov/protocolDevelopment/electronic_applications/ctc.htm\#ctc_50 [Last accessed on May 21, 2020]

22 Aleixo GFP, Shachar SS, Nyrop KA, Muss HB, Battaglini CL and Williams GR: Bioelectrical impedance analysis for the assessment of sarcopenia in patients with cancer: a systematic review. Oncologist 25(2): 170-182, 2020. PMID: 32043785. DOI: 10.1634/theoncologist.2019-0600

23 Yang M, Shen Y, Tan L and Li W: Prognostic value of sarcopenia in lung cancer: asystematic review and meta-analysis. Chest 156(1): 101-111, 2019. PMID: 31128115. DOI: 10.1016/j.chest.2019.04.115

24 Korniluk A, Koper O, Kemona H and Dymicka-Piekarska V: From inflammation to cancer. Ir J Med Sci 186(1): 57-62, 2017. PMID: 27156054. DOI: 10.1007/s11845-016-1464-0

25 Lorenzo I, Serra-Prat M and Yebenes JC: The role of water homeostasis in muscle function and frailty: a review. Nutrients 11(8): E1857, 2019. PMID: 31405072. DOI: 10.3390/nu11081857

26 McManus ML, Churchwell KB and Strange K: Regulation of cell volume in health and disease. N Engl J Med 333(19): 1260-1266, 1995. PMID: 7566004. DOI: 10.1056/NEJM199511093331906

27 Burg MB, Ferraris JD and Dmitrieva NI: Cellular response to hyperosmotic stresses. Physiol Rev 87(4): 1441-1474, 2007. PMID: 17928589. DOI: 10.1152/physrev.00056.2006 
28 Brocker C, Thompson DC and Vasiliou V: The role of hyperosmotic stress in inflammation and disease. Biomol Concepts 3(4): 345-364, 2012. PMID: 22977648. DOI: 10.1515/bmc-2012-0001

29 Cowen LE, Hodak SP and Verbalis JG: Age-associated abnormalities of water homeostasis. Endocrinol Metab Clin North Am 42(2): 349-370, 2013. PMID: 23702406. DOI: 10.1016/j.ec1.2013.02.005

30 Nishiyama VKG, Albertini SM, Moraes CMZG, Godoy MF and Netinho JG: Malnutrition and clinical outcomes in surgical patients with colorectal disease. Arq Gastroenterol 55(4): 397402, 2018. PMID: 30785525. DOI: 10.1590/S00042803.201800000-85

31 Oya S, Yamashita H, Iwata R, Kawasaki K, Tanabe A, Yagi K, Aikou S and Seto Y: Perioperative fluid dynamics evaluated by bioelectrical impedance analysis predict infectious surgical complications after esophagectomy. BMC Surg 19(1): 184, 2019. PMID: 31791292. DOI: 10.1186/s12893-019-0652-z

32 Axelsson L, Silander E, Bosaeus I and Hammerlid E: Bioelectrical phase angle at diagnosis as a prognostic factor for survival in advanced head and neck cancer. Eur Arch Otorhinolaryngol 275(9): 2379-2386, 2018. PMID: 30046911. DOI: $10.1007 / \mathrm{s} 00405-018-5069-2$
33 Gupta D, Lammersfeld CA, Vashi PG, King J, Dahlk SL, Grutsch JF and Lis CG: Bioelectrical impedance phase angle in clinical practice: implications for prognosis in stage IIIB and IV non-small cell lung cancer. BMC Cancer 9: 37, 2009. PMID: 19175932. DOI: $10.1186 / 1471-2407-9-37$

34 Castanho IA, Lopes AJ, Koury JC, Tessarollo B, Silva AC and Nunes RA: Relationship between the phase angle and volume of tumours in patients with lung cancer. Ann Nutr Metab 62(1): 6874, 2013. PMID: 23257390. DOI: 10.1159/000345588

Received April 19, 2020

Revised April 23, 2020

Accepted May 26, 2020 